\title{
Evaluation of the water absorption and pyroplastic deformation of alumina-strengthened porcelain with talc-addition
}

\author{
Dong HAO ${ }^{1}$, Takashi AKATSU ${ }^{1,2, \dagger}$ and Nobuaki KAMOCHI ${ }^{3}$ \\ ${ }^{1}$ Ceramic Research Center, Saga University, 2441-1 Oono-otsu, Arita-cho, Nishimatsuura-gun, Saga 844-0013, Japan \\ ${ }^{2}$ Faculty of Art and Regional Design, Saga University, 1 Honjo, Saga 840-8502, Japan \\ ${ }^{3}$ Saga Ceramies Research Laboratory, 3037-7 Hei Kuromuta, Arita-cho, Nishimatsuura-gun, Saga 844-0022, Japan
}

\begin{abstract}
The water absorption (WA) and pyroplastic deformation (PD) of alumina-strengthened porcelain with talcaddition is examined to develop porcelain with optimized properties for a wide range of firing temperatures. An increase in talc amount enhances the porcelain densification, i.e. decreases WA and the increase in sintering shrinkage which accelerates PD, because it leads to an increase in the amount of liquid phase with a low viscosity during firing. On the other hand, talc and Gairome clay addition yields rigid crystalline microstructures in the glass matrix of the porcelain, which suppresses PD. As a result, optimized properties, i.e. WA less than $0.5 \%$ and pyroplastic deformation index less than $1.5 \times 10^{-6} \mathrm{~mm}^{-1}$, are realized in porcelain with 2 mass $\%$ talc addition in a wide firing temperature range from 1240 to $1384^{\circ} \mathrm{C}$.

@2020 The Ceramic Society of Japan. All rights reserved.
\end{abstract}

Key-words : Porcelain, Densification, Mullite, Pyroplastic deformation

[Received November 11, 2019; Accepted January 27, 2020]

\section{Introduction}

Porcelain is widely used in tableware, sanitary ware, insulators, and other ceramic items worldwide. Pyroplastic deformation (PD) of porcelain is a kind of distortion which occurs during firing of the porcelain green body and is caused by sintering shrinkage and/or the viscous flow of a liquid phase accelerated by different applied stresses such as gravity. ${ }^{1)-3)}$ The fired porcelain products can lose their functions or aesthetic properties due to large deformations or distortions. Therefore, it is crucial to significantly reduce $\mathrm{PD}$ across a wide firing temperature range so that the original dimensions of porcelain products can be maintained.

In the long history of porcelain production, great efforts have been made to avoid or reduce PD as well as to lessen water absorption (WA). ${ }^{1) 2}$ ) Three general strategies have been adopted to prevent large porcelain PD. The first strategy is to manage the sintering process, such as firing temperature ramp rate, maximum firing temperature, and dwell time. ${ }^{4)}$ The second is to control the microstructure of the porcelain green body through the preparation technique. Recently, Conserva et al. investigated the different impacts of wet and dry processes on the PD of stoneware. ${ }^{5)}$ They found that the PD of green bodies prepared by the dry route, which had a heterogeneous microstructure, was less than that by the wet route because of the lower liquid

\footnotetext{
Corresponding author: T. Akatsu; E-mail: akatsu@cc.sagau.ac.jp
}

phase mobility in the heterogeneous porcelain at elevated temperatures. The third strategy is to optimize the porcelain chemical composition by modifying the ratio of raw materials or by the addition of certain minerals in order to control the chemical reaction products during firing.

Chemical composition differences affect densification with a liquid phase and the PD of porcelain through the evolution of a glass matrix and mullite crystals. Particularly, the influence of alkali and alkaline earth oxides on PD such as calcite, dolomite, magnesite and talc, ${ }^{2)}$ calcium oxide, ${ }^{3)}$ nepheline syenite, ${ }^{6)}$ spodumene, ${ }^{7)}$ waste glass, ${ }^{8)}$ and feldspar ${ }^{4), 9)}$ has been intensively investigated. The ratio of $\mathrm{SiO}_{2}$ to $\mathrm{Al}_{2} \mathrm{O}_{3}$ and the addition of certain minerals are other factors that have been investigated by using andalusite, ${ }^{10)}$ illite, ${ }^{11)}$ etc. Previous studies have shown that a change in the alkali/alkaline earth oxides ratio had a greater effect on the densification and $\mathrm{PD}$ of porcelain than changing the $\mathrm{SiO}_{2} / \mathrm{Al}_{2} \mathrm{O}_{3}$ ratio.9),12) In addition to the effect of glass matrix and mullite formation on reducing PD, some researchers also proposed to increase the viscosity of the liquid phase by introducing or forming crystals with a high melting point as a filler. ${ }^{13}$ )

Talc is a mineral which includes magnesium, which enhances the glass matrix formation in porcelain. ${ }^{11)}$ Furthermore, the cordierite which crystallizes during the firing of porcelain with talc can be used as a strengthening filler or to reduce PD. ${ }^{13), 14)}$ Bernardin et al. found that talc exhibited a small influence on PD, except for large talc additions over $40 \mathrm{wt} \%{ }^{15)}$ Magagnin et al. studied the influence of talc addition to a porcelain tile on PD and 
Table 1. Chemical compositions of raw materials for porcelain fabrication

\begin{tabular}{cccccccccc}
\hline Raw materials & $\begin{array}{c}\mathrm{Ig} \text { loss } \\
\text { /mass \% }\end{array}$ & $\begin{array}{c}\mathrm{SiO}_{2} \\
\text { /mass \% }\end{array}$ & $\begin{array}{c}\mathrm{Al}_{2} \mathrm{O}_{3} \\
\text { /mass \% }\end{array}$ & $\begin{array}{c}\mathrm{Fe}_{2} \mathrm{O}_{3} \\
\text { /mass \% }\end{array}$ & $\begin{array}{c}\mathrm{TiO}_{2} \\
\text { /mass \% }\end{array}$ & $\begin{array}{c}\mathrm{CaO} \\
\text { /mass \% }\end{array}$ & $\begin{array}{c}\mathrm{MgO} \\
\text { /mass \% }\end{array}$ & $\begin{array}{c}\mathrm{Na}_{2} \mathrm{O} \\
/ \text { mass \% }\end{array}$ & $\begin{array}{c}\mathrm{K}_{2} \mathrm{O} \\
/ \text { mass \% }\end{array}$ \\
\hline Amakusa clay & 3.69 & 74.32 & 17.41 & 0.50 & 0.02 & 0.08 & 0.08 & 0.09 & 3.52 \\
Motoyama gairome clay & 12.79 & 48.81 & 34.99 & 1.1 & 0.61 & 0.22 & 0.21 & 0.09 & 0.96 \\
Masuda feldspar & 0.64 & 66.32 & 18.59 & 0.07 & $\mathrm{Tr}$. & 0.06 & 0.04 & 3.26 & 10.35 \\
Calcined talc & 1.31 & 62.82 & 2.9 & 0.17 & 0.01 & 0.56 & 31.71 & 0.03 & 0.02 \\
Alumina & 0.02 & 0.03 & 99.6 & 0.02 & - & - & - & 0.37 & - \\
\hline
\end{tabular}

Table 2. Raw material compositions of porcelain samples

\begin{tabular}{cccccc}
\hline & $\begin{array}{c}\text { Amakusa clay } \\
/ \text { mass } \%\end{array}$ & $\begin{array}{c}\text { Motoyama gairome clay } \\
/ \text { mass } \%\end{array}$ & $\begin{array}{c}\text { Masuda feldspar } \\
/ \text { mass } \%\end{array}$ & $\begin{array}{c}\text { Calcined talc } \\
/ \text { mass } \%\end{array}$ & $\begin{array}{c}\text { Alumina } \\
/ \text { mass } \%\end{array}$ \\
\hline STD & 60 & 0 & 10 & 0 & 30 \\
0T & 43.9 & 12.2 & 7.3 & 0 & 36.6 \\
2T & 43.0 & 12 & 7.2 & 2 & 35.9 \\
6T & 41.3 & 11.5 & 6.9 & 6 & 34.4 \\
18T & 36 & 10 & 5.7 & 18 & 30 \\
22T & 34.3 & 9.5 & 52 & 28.5 \\
\hline
\end{tabular}

concluded that talc caused a tendency towards large deformation due to a decrease in the viscosity of the liquid phase. ${ }^{11)}$ However, they ignored the effect of the enhanced crystallization of cordierite on the liquid phase viscosity. Kamochi et al. ${ }^{13)}$ investigated the effect of talc addition to alumina-strengthened porcelain on PD. The fired porcelain had a very low pyroplastic deformation index (PI) of less than $1.5 \times 10^{-6} \mathrm{~mm}^{-1}$ even at a firing temperature $100^{\circ} \mathrm{C}$ higher than that at which the maximum densification was observed. They proposed that the main reason is the formation of cordierite crystals, which constructed a complicated structure in the porcelain and impeded PD. Consequently, talc addition to porcelain is an attractive option for reducing PD at high firing temperatures. However, the influence of talc addition on the WA and PI of porcelain remains quantitatively unknown. Moreover, the mechanism for PD prevention requires further investigation in order to realize extremely low PI $\left(<1.5 \times 10^{-6} \mathrm{~mm}^{-1}\right.$, for instance) and WA ( $<0.5 \%$, for instance) for a wide firing temperature range.

In this study, the WA and PI of alumina-strengthened porcelain with talc-addition made from Amakusa clay was quantitatively examined. PD tests at elevated temperatures were performed to evaluate the ability to prevent PD through the quantification of PI. The mechanism of PD prevention is clarified through observations of the firing temperature dependence of WA, bulk density (BD), PI, and evolution of the crystalline phase and microstructure. This study provides feasible technical support for the design and preparation of alumina-strengthened porcelain with low WA and PI in a wide firing temperature range.

\section{Experimental}

\subsection{Raw materials}

Commercial-grade raw material powders were used in this study, i.e. Amakusa clay (Fuchino Ceramic Raw Materials Co., Japan), Masuda feldspar (Nishi-Nihon Kogyo Co., Japan), Motoyama gairome clay (KCM Co., Japan) and calcined talc. Alumina powder (A-34, Japan Light
Metal Co., Japan) with a mean diameter of approximately $4 \mu \mathrm{m}$ was used to make the alumina-strengthened porcelain. The chemical compositions of the raw materials are listed in Table 1.

\subsection{Preparation of porcelain green bodies}

The specimens used in this study were fabricated into test bars by slip-casting in a plaster mould. The slurry for casting was made by ball-milling of all the raw material powders for $1 \mathrm{~h}$ to disperse the powders in water uniformly with a dispersant (A-6012, TOAGOSEI Co., Ltd., Japan), in which the water concentration was set to 28 mass \%. As a result of ball milling, the mean diameter of the powders was confirmed to be approximately $7 \mu \mathrm{m}$, which was measured by laser diffraction (Laser Micron Sizer LMS-2000e, Seishin Enterprize Co., Japan). Each green body was prepared at dimensions of $120 \times 20 \times 7 \mathrm{~mm}^{3}$.

The raw material composition for each porcelain is listed in Table 2. Five different types of green bodies were fabricated and noted as $x \mathrm{~T}$, where $x$ refers to the amount of talc addition ranging from 0 to 22 mass $\%$. For example, $2 \mathrm{~T}$ indicates the porcelain containing 2 mass $\%$ of talc. For reference, conventional alumina-strengthened porcelain, denoted as STD, was also fabricated without the addition of Gairome clay or talc. According to the chemical compositions of the raw materials and the raw material composition of each porcelain, the chemical compositions of the porcelains were calculated as shown in Table 3. The ratio of $\mathrm{SiO}_{2} / \mathrm{Al}_{2} \mathrm{O}_{3}$ varies from 0.88 to 1.21 , which is relatively low compared with that of the previous study. ${ }^{9}$ Tuncel et al. found that a lower $\mathrm{SiO}_{2} / \mathrm{Al}_{2} \mathrm{O}_{3}$ ratio leads to enhancement of the crystallization of mullite, ${ }^{9)}$ which indicates that a large amount of mullite formation in the porcelain should have occurred in this study. Although the ratio of raw materials changed for each porcelain sample, $\mathrm{Na}_{2} \mathrm{O} / \mathrm{K}_{2} \mathrm{O}$ remained almost constant at 0.18 . It should be noted that all the samples had different $\mathrm{MgO}$ contents due to the addition of different amounts of talc, which implies that cordierite crystallization and glass matrix formation 
Table 3. Chemical compositions of porcelain samples before firing

\begin{tabular}{cccccccccc}
\hline & $\begin{array}{c}\text { Ig. Loss } \\
\text { /mass } \%\end{array}$ & $\begin{array}{c}\mathrm{SiO}_{2} \\
\text { mass } \%\end{array}$ & $\begin{array}{c}\mathrm{Al}_{2} \mathrm{O}_{3} \\
/ \text { mass } \%\end{array}$ & $\begin{array}{c}\mathrm{Fe}_{2} \mathrm{O}_{3} \\
/ \text { mass } \%\end{array}$ & $\begin{array}{c}\mathrm{TiO}_{2} \\
/ \text { mass } \%\end{array}$ & $\begin{array}{c}\mathrm{CaO} \\
/ \text { mass \% }\end{array}$ & $\begin{array}{c}\mathrm{MgO} \\
/ \text { mass \% }\end{array}$ & $\begin{array}{c}\mathrm{Na}_{2} \mathrm{O} \\
/ \text { mass } \%\end{array}$ & $\begin{array}{c}\mathrm{K}_{2} \mathrm{O} \\
/ \text { mass } \%\end{array}$ \\
\hline $\mathrm{STD}$ & 2.28 & 51.23 & 42.19 & 0.31 & 0.01 & 0.05 & 0.05 & 0.49 & 3.15 \\
0T & 3.23 & 43.43 & 49.72 & 0.37 & 0.08 & 0.07 & 0.06 & 0.42 & 2.42 \\
$2 \mathrm{~T}$ & 3.20 & 43.86 & 48.84 & 0.36 & 0.08 & 0.08 & 0.70 & 0.42 & 2.37 \\
$6 \mathrm{~T}$ & 3.12 & 44.66 & 46.93 & 0.35 & 0.08 & 0.10 & 1.96 & 0.40 & 2.28 \\
$18 \mathrm{~T}$ & 2.89 & 46.93 & 41.28 & 0.33 & 0.07 & 0.16 & 5.76 & 0.35 & 1.99 \\
$22 \mathrm{~T}$ & 2.81 & 47.74 & 39.38 & 0.32 & 0.07 & 0.17 & 7.03 & 0.34 & 1.89 \\
\hline
\end{tabular}

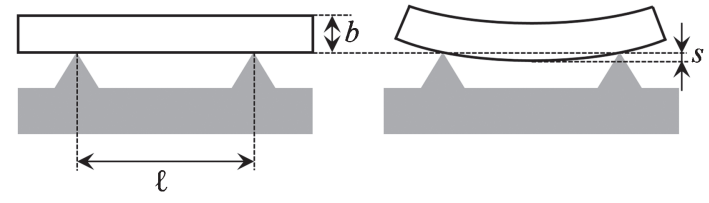

Fig. 1. Schematic of specimen for the PD test before (left) and after (right) firing.

during firing at high temperatures strongly depends on $\mathrm{MgO}$ content. The viscosity of the liquid phase formed during firing should also decrease with increasing $\mathrm{MgO}$ content. Thus, the influence of the talc amount on both WA and PI was carefully investigated in this study.

\subsection{Characterization}

$\mathrm{X}$-ray diffraction (XRD) was conducted by using an Xray diffractometer equipped with an X-ray radiation generator $(\mathrm{Cu}-\mathrm{K} \alpha, \lambda=0.15418 \mathrm{~nm})$ across a scanning angle (2 $\theta)$ range of $5-80^{\circ}$ (RINT2100, Rigaku Corp., Japan). In order to observe the microstructures of the fired specimens, the specimens were mirror polished then etched by 5 mass \% Hydrofluoric acid solution for $30 \mathrm{~s}$. The etched specimens were observed by using a field-emission scanning electron microscope with an energy dispersive X-ray spectrometry system (JSM-6700FSS, JEOL Corp., Japan). The BD and WA of fired specimens were evaluated based on the Archimedes principle according to ASTM C373.

\subsection{Test for PD}

After drying the casted specimens at room temperature for two days, two ends of the green bodies were suspended on a specially fabricated alumina support with a span of $100 \mathrm{~mm}$. A schematic of a PD test specimen before and after firing is shown in Fig. 1. The PD tests were performed in a muffle furnace in air at maximum firing temperatures (MFTs) ranging from 1150 to $1400^{\circ} \mathrm{C}$, which was held for $1 \mathrm{~h}$. The firing temperature ramp rate was $200^{\circ} \mathrm{C} / \mathrm{h}$. MFT was monitored by using a reference thermometer (type L and M, JFCC, Japan) which was set near the specimen in the furnace. PI was calculated by the following equation:6),16)

$$
\mathrm{PI}=\frac{s b^{2}}{\ell^{4}}
$$

where $s$ the maximum deformation ( $\mathrm{mm}), b$ the thickness of the specimen $(\mathrm{mm})$, and $\ell$ is the distance between the two supports (mm) (see Fig. 1).

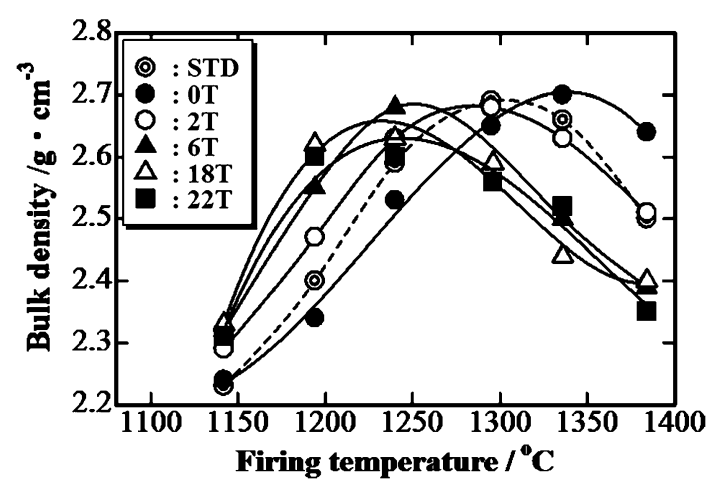

Fig. 2. BD of porcelain as a function of MFT.

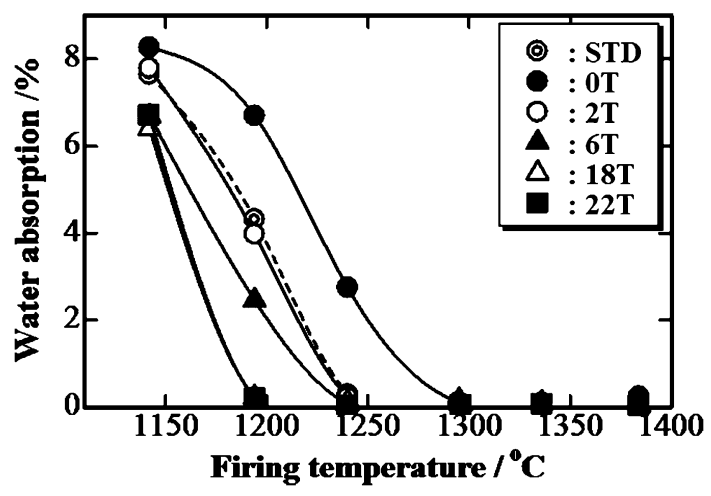

Fig. 3. WA of porcelain as a function of MFT.

\section{Results and discussion}

3.1 Effect of talc addition to aluminastrengthened porcelain on densification

Figures 2 and $\mathbf{3}$ present the BD and WA, respectively, of alumina-strengthened porcelain as a function of MFT. The changes in BD and WA as a function of MFT were categorized into three MFT regions:

(I) $\mathrm{BD}$ increases with increasing MFT in the relatively low-temperature range, where WA decreases significantly with increasing MFT.

(II) $\mathrm{BD}$ is maximized at the MFT where WA becomes less than $0.5 \%$.

(III) $\mathrm{BD}$ decreases with increasing MFT in the relatively high-temperature range, where WA remains below $0.5 \%$.

For the porcelain in this study, the amount of liquid phase formed during firing increases with increasing MFT because of the activated dissolution of quartz into the liquid phase (see Fig. 4). Especially for 2T, an increase in 
the amount of liquid phase was confirmed by an increase in the XRD intensity of the halo pattern at approximately $2 \theta=23.0-24.0^{\circ}$ as shown in Fig. 4 because the liquid phase mostly transforms to a glass matrix at ambient
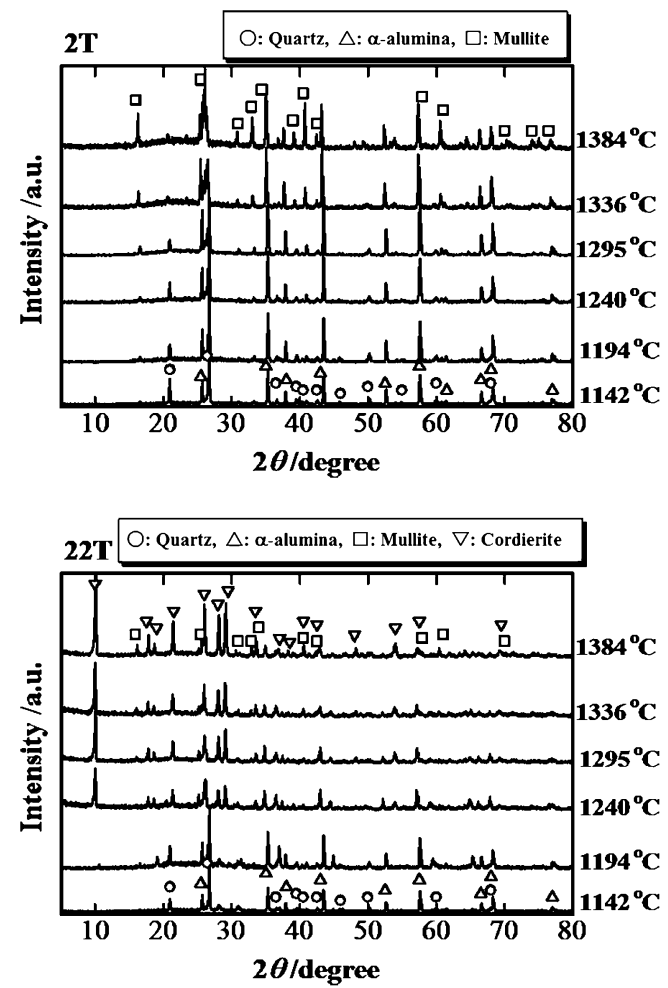

Fig. 4. XRD profiles of $2 \mathrm{~T}$ and $22 \mathrm{~T}$ porcelain as a function of MFT. temperatures. In addition, the viscosity of the liquid phase decreases with increasing MFT. ${ }^{17)}$ Both of these processes accelerate the liquid phase sintering and thus densify the porcelain in region (I). Densification at a low firing temperature realized by talc addition was also reported by Biasini et al. ${ }^{17)}$

The decrease in BD with increasing MFT in region (III) is basically described by pore formation, called bloating, $\left.{ }^{16}\right)$ being enhanced by the increased firing temperature (see Fig. 5). As for the porcelain in this study, the pores occurring in regions (II) and (III) are very small (<approximately $30 \mu \mathrm{m}$, see Fig. 5), and thus WA is less than $0.5 \%$ even when a decrease in BD occurs. The small pore formation, or prevention of large pore formation in other words, is due to the low viscosity of the liquid phase during firing caused by the doping of magnesium ions that fragment the $\mathrm{SiO}_{4}$-tetrahedra network structure of the $\mathrm{SiO}_{2}$-based liquid, ${ }^{18)}$ and also to a rigid fine microstructure which consists of numerous fine crystals evolving with increasing MFT (see Fig. 6).

The maximum $\mathrm{BD}$ and temperature at which the maximum $\mathrm{BD}$ occurs in region (II) tend to decrease with increasing amount of talc (see Fig. 2). This is attributed to the following reasons:

(1) The increase in the amount of glass matrix (see halo pattern at approximately $2 \theta=23.0-24.0^{\circ}$ in Fig. 7) caused by the doping of magnesium ions, which accelerates the dissolution of quartz into the liquid phase during firing;

(2) The decrease in the viscosity of the liquid phase during firing due to the doping of magnesium ions, as discussed above;
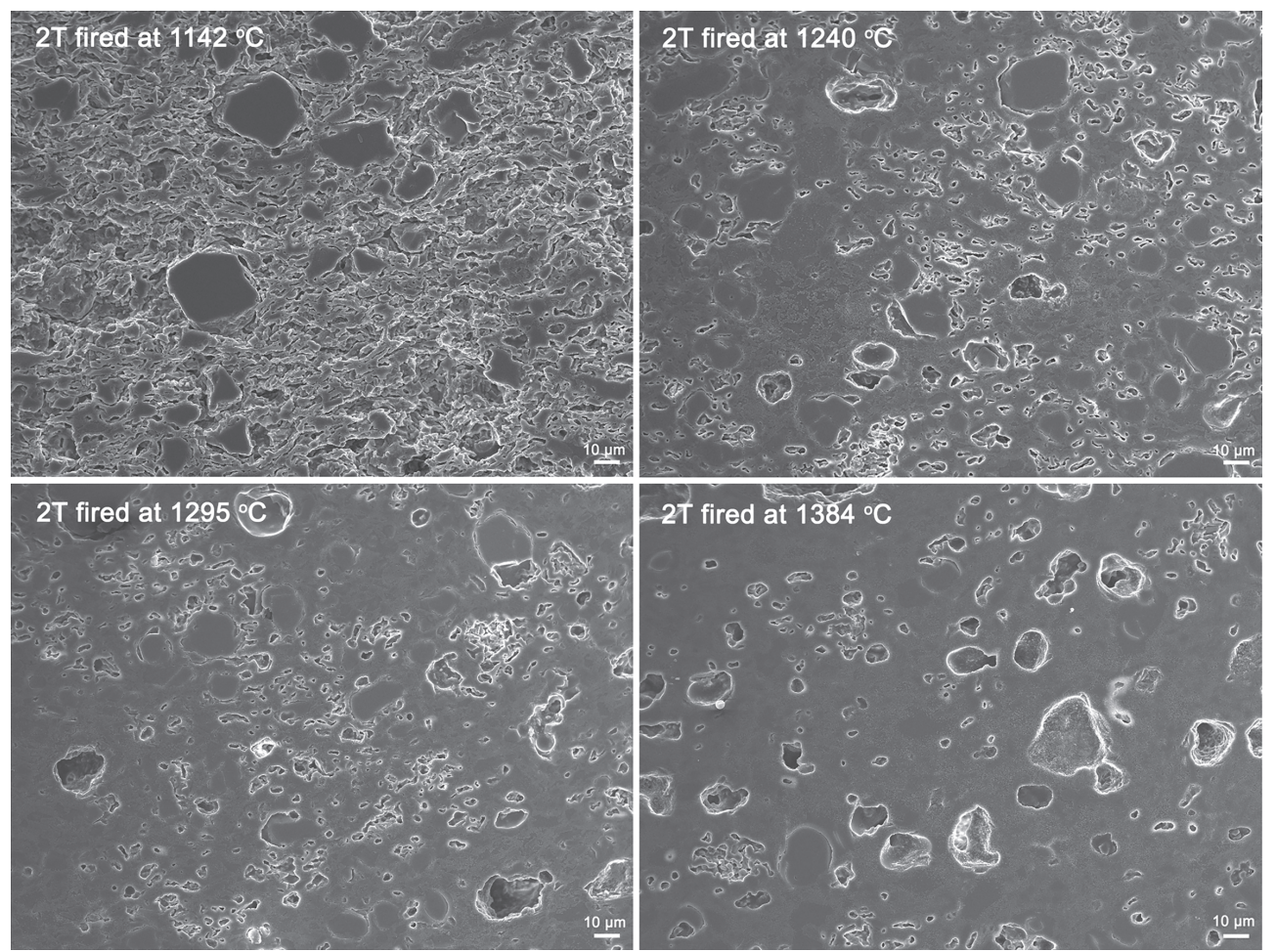

Fig. 5. Microstructural evolution of pores in $2 \mathrm{~T}$ porcelain as a function of MFT observed with a scanning electron microscope. 

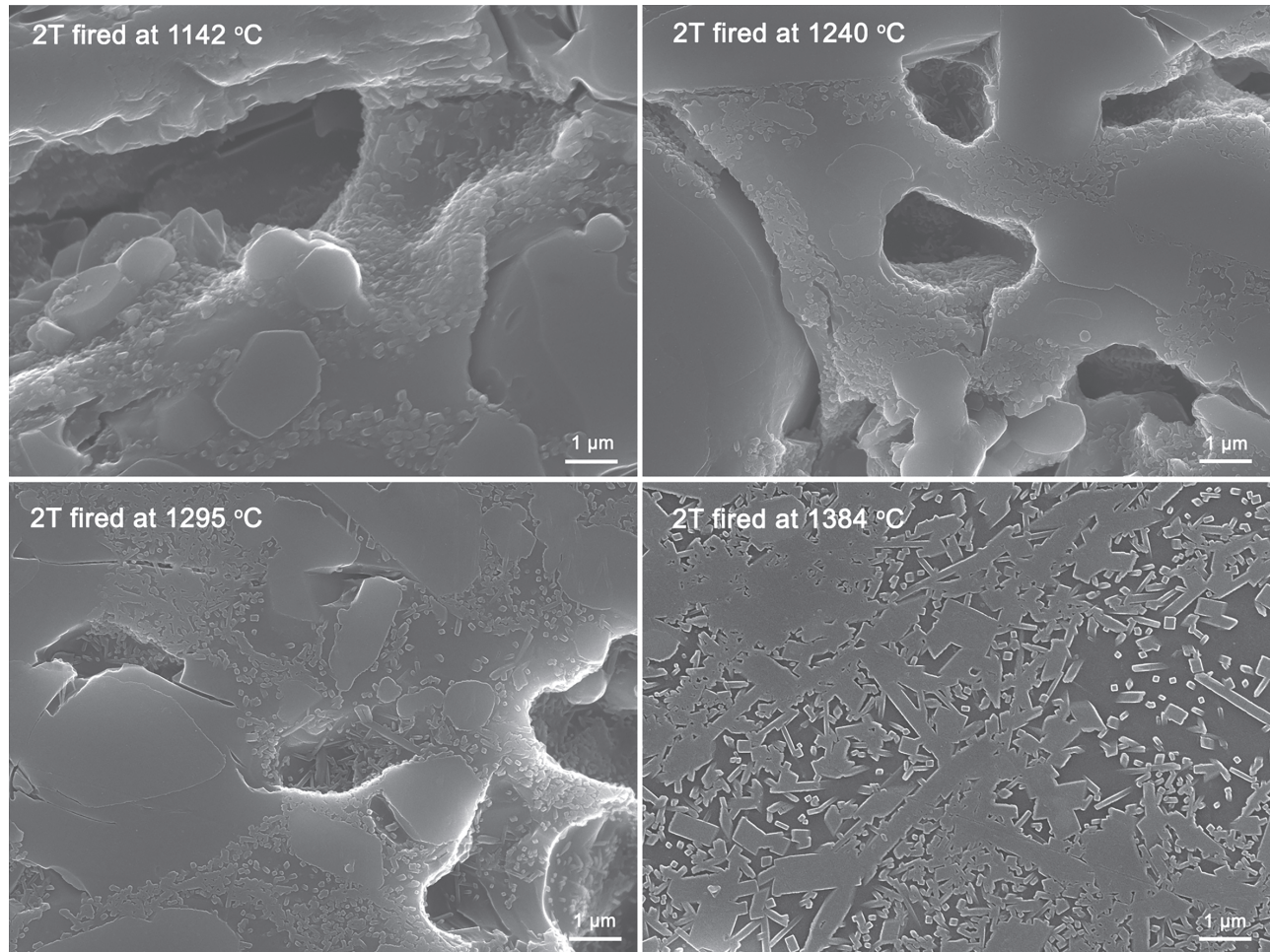

Fig. 6. Microstructural evolution of mullite crystals in $2 \mathrm{~T}$ porcelain as a function of MFT observed with a scanning electron microscope.

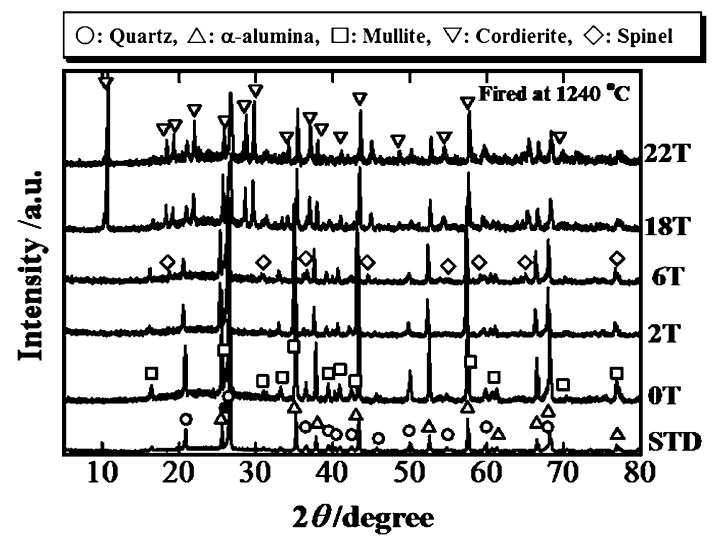

Fig. 7. XRD profiles of porcelain fired at $1240^{\circ} \mathrm{C}$ as a function of the amount of added talc.

(3) The decrease in the amount of alumina, which has a higher density of $3.98 \mathrm{~g} / \mathrm{cm}^{3}$ than any other crystals or glass matrix in the porcelain. This is simply caused by the addition of a relatively small amount of alumina owing to the addition of a large amount of talc according to the balance of raw materials (see Table 2).

The consumption of doped alumina to produce mullite and cordierite crystals during firing (see Fig. 4) may also contribute to the decrease in the amount of alumina, in which a chemical reaction is activated between alumina and the liquid phase with a relatively large amount of magnesium ions. However, the impact of this crystallization on the decreasing amount of alumina must be small; otherwise, the reduction of the liquid phase due to crys-

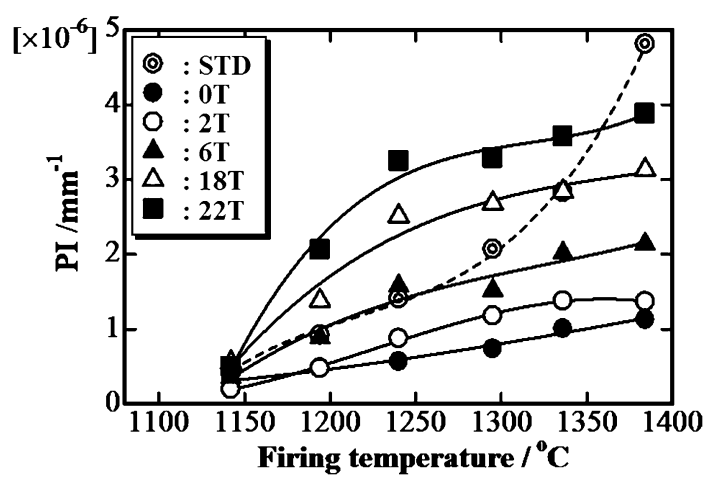

Fig. 8. PI of porcelain as a function of MFT.

tallization would prevent the densification of porcelain along with talc addition, which does not agree with the experimental results shown in Figs. 2 and 3.

\subsection{Effect of talc addition to alumina- strengthened porcelain on PD}

Figure 8 shows the PI values of alumina-strengthened porcelain with MFTs ranging from 1150 to $1400^{\circ} \mathrm{C}$. The PI value of STD increases monotonically with increasing MFT. On the other hand, the PI of the other porcelain samples increases with increasing MFT at lower firing temperatures and saturates at higher temperatures. The saturated PI value becomes larger with increasing amount of talc.

The PD of the porcelain in this study is essentially promoted by sintering shrinkage, which is why a clear increase in PI occurs up to the MFT at which BD is 

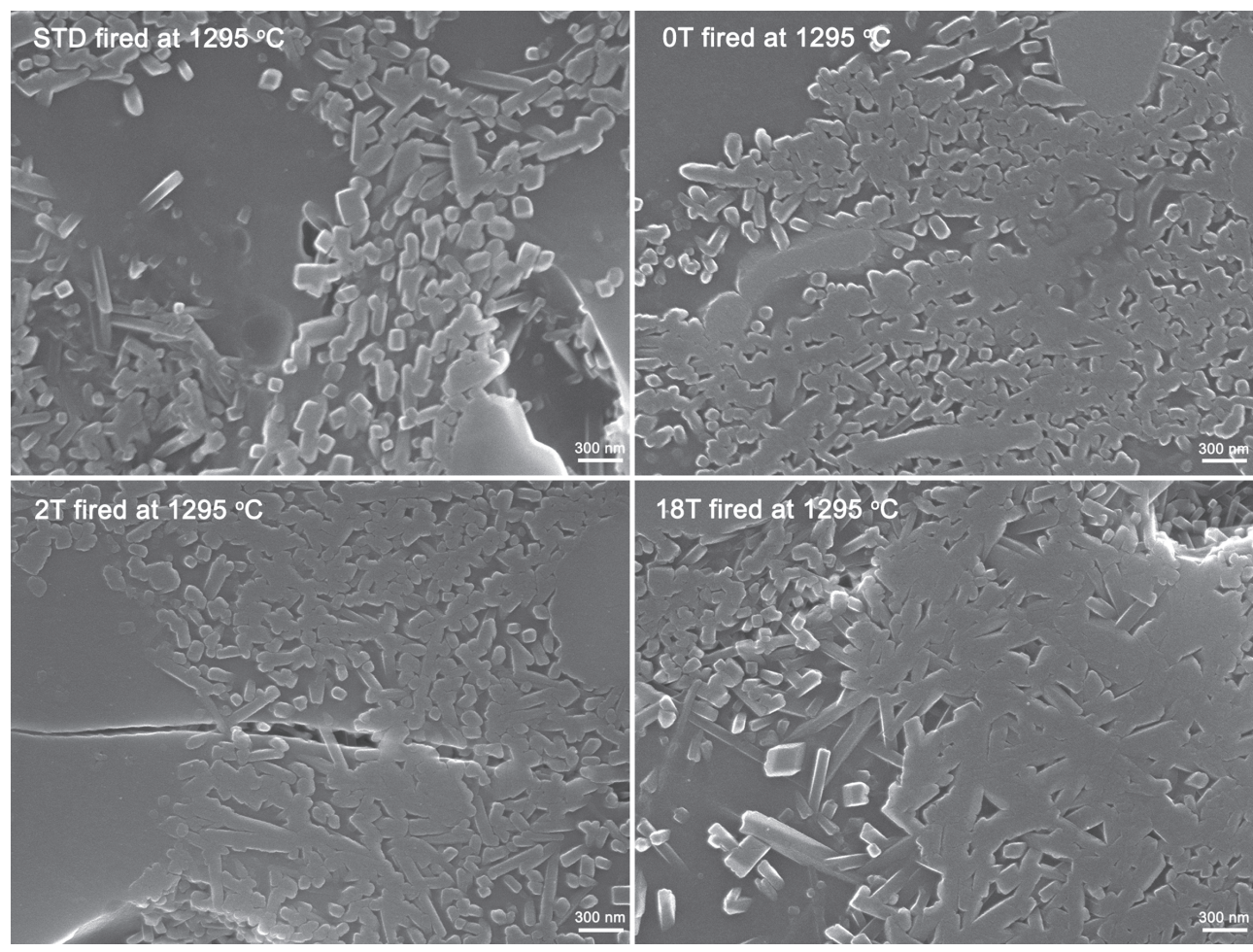

Fig. 9. Microstructural evolution of mullite crystals in STD, 0T, 2T, and $18 \mathrm{~T}$ porcelain fired at $1295^{\circ} \mathrm{C}$ observed with a scanning electron microscope.

maximized. The PD of STD progresses beyond the MFT because the viscous flow of the liquid phase leads to a large PD at high firing temperatures. For the $x \mathrm{~T}$ porcelains, PI is almost saturated or slowly increasing beyond the MFT at which the porcelain is maximally densified. This clearly indicates that the $x \mathrm{~T}$ porcelains consist of rigid microstructures composed of fine crystals (see Fig. 6) which prevent a large PD at high firing temperatures, even though the viscosity of the liquid phase in the porcelain is lower than that in STD because of the magnesium doping. As mentioned in Section 3.1, the increase in talc amount enhances the densification, i.e. shrinkage due to liquid phase sintering, owing to reasons (1) and (2). This is why the saturated PI of the $x \mathrm{~T}$ porcelains increases with increasing amount of talc.

The addition of talc to the porcelain has both an advantage and disadvantage for realizing a low PI. The advantage is the acceleration of the crystallization of cordierite (see Fig. 7), which contributes to the formation of the rigid porcelain microstructure. The disadvantage is the enhanced formation of a liquid phase with a low viscosity during firing (see halo pattern at approximately $2 \theta=23.0$ $24.0^{\circ}$ in Fig. 7). For the $x \mathrm{~T}$ porcelains in this study, a small amount of talc addition results in a small PI (see Fig. 8). This clearly indicates that cordierite crystallization is not so effective to suppress PD in region (I). The formation of a rigid microstructure which mainly consists of needle-like mullite crystals surrounded by a small amount of liquid phase with a low viscosity is key to realizing a small PI for the porcelain in this study (see Fig. 9). This is a new strategy to obtain porcelain with low WA and low PI, which is different from that of Ref. 13 where the formation of a continuous network of cordierite is emphasized to construct the rigid microstructure. Different from the previous study, ${ }^{13)}$ although porcelain $2 \mathrm{~T}$ contains smaller amount of the talc, 2 versus 18 mass \%, it achieves the aim of both small WA and small PI in a wide fire temperature range from 1240 to $1384{ }^{\circ} \mathrm{C}$. On the contrary, STD can only achieve such purpose at $1240^{\circ} \mathrm{C}$ (see Figs. 3 and 8). The crystallization and crystal growth of needle-like mullite in the $x \mathrm{~T}$ porcelains is more notable than that in STD (see Figs. 7 and 9). This indicates that the addition of Gairome clay to the porcelain is effective for enhancing mullite crystallization (see Fig. 9).

\section{Conclusion}

The WA and PI of alumina-strengthened porcelain with talc-addition was examined to develop porcelain with optimized properties for a wide range of MFTs. An increased amount of added talc enhances the densification of the porcelain, i.e. decreases WA and the increase in sintering shrinkage which accelerates PD, because it leads to an increase in the amount of liquid phase with a low viscosity during firing. On the other hand, the addition of talc and Gairome clay yields a rigid crystalline microstructure in the porcelain glass matrix, which suppresses PD. The key to realizing low porcelain WA and PI for a wide range of MFTs is to form a rigid microstructure which mainly consists of needle-like mullite crystals surrounded by a small amount of low-viscosity liquid phase. As a result, 2 mass $\%$ talc addition to the porcelain results in optimized properties, i.e. WA less than $0.5 \%$ and PI less than $1.5 \times$ 
$10^{-6} \mathrm{~mm}^{-1}$, across a rather wide firing temperature range from 1240 to $1384^{\circ} \mathrm{C}$ as compare to that of STD, observed only at $1240{ }^{\circ} \mathrm{C}$. A comparison of WA and PI between STD and $2 \mathrm{~T}$ demonstrates the effect of talc and Gairome clay addition to the porcelain towards the optimization mentioned above, where the PI of $2 \mathrm{~T}$ is much smaller than that of STD in a wide range of MFTs despite there being almost no difference in WA between them.

Acknowledgments This work was partially supported by JSPS KAKENHI [grant number 18K04753] and collaborated research fund by TOTO, Japan. We also would like to express our sincere gratitude to Dr. Atsunori Shiraishi and Dr. Asami Otake from Saga Ceramics Research Laboratory, Japan for their assistance with scanning electron microscope observations.

\section{References}

1) M. Romero and J. Pérez, Mater. Construcc., 65, e065 (2015).

2) E. Sánchez, V. Sanz, E. Cañas, J. Sales, K. Kayacı and M. U. Taşkıran, J. Eur. Ceram. Soc., 39, 601-609 (2019).

3) F. Güngör, Ceram. Int., 44, 13360-13366 (2018).

4) A. Bresciani and B. Spinelli, Cfi-Ceram. Forum Int., 89, No. 6-7, E41-E45 (2012).

5) L. R. dos Santos Conserva, F. G. Melchiades, S. Nastri, A. O. Boschi, M. Dondi and G. Guarini, J. Eur. Ceram.
Soc., 37, 333-342 (2017).

6) T. Aydına, N. Kunduracı and A. Akbay, Sci. Sinter., 50, 85-94 (2018).

7) T. Aydin and A. Kara, J. Ceram. Process. Res., 15, 486491 (2014).

8) E. Rambaldi, W. M. Carty, A. Tucci and L. Esposito, Ceram. Int., 33, 727-733 (2007).

9) D. Y. Tuncel and E. Ozel, Ceram. Int., 38, 1399-1407 (2012).

10) T. F. Deng, B. Liu, X. H. Xu and J. F. Wu, J. Ceram. Soc. Jpn., 123, 1004-1009 (2015).

11) D. Magagnin, C. M. F. Dos Santos, A. Wanderlind, J. Jiusti and A. De Noni, Jr., Mater. Sci. Eng. A, 618, 533539 (2014).

12) N. Tamsu, A. V. Bayrak and H. Ozdemir, Acta. Phys. Pol. A, 123, 283-284 (2013).

13) N. Kamochi, K. Nishiyama and H. Katsuki, J. Ceram. Soc. Jpn., 124, 787-790 (2016).

14) Y. Kobayashi, J. Soc. Powder Technol., Jpn., 38, 338346 (2001).

15) A. M. Bernardin, D. S. De Medeiros DS and H. G. Riella, Mater. Sci. Eng. A, 427, 316-319 (2006).

16) S. M. Olhero, G. Tarì and J. M. F. Ferreira, J. Am. Ceram. Soc., 84, 719-725 (2001).

17) V. Biasini, M. Dondi, G. Guarini, M. Raimondo, A. Argnani and S. Di Primio, Silic. Ind., 68, 67-73(2003).

18) R. Gill, "Chemical fundamentals of geology and environmental geoscience", Wiley, Blackwell (2014) pp. 133-135. 